\section{OP0069 MICROCHIMERISM AND SJÖGREN? S SYNDROME: A PRELIMINARY STUDY ON SALIVARY GLANDS}

${ }^{1} \mathrm{~F}$ Carlucci, ${ }^{2} \mathrm{~A}$ Stoppacciaro, ${ }^{1} \mathrm{R}$ Priori, ${ }^{1} \mathrm{~F}$ Barone, ${ }^{1} \mathrm{C}$ Alessandri, ${ }^{1} \mathrm{G}$ Valesini. ${ }^{1}$ Divisione Di Reumatologia; 'Istituto Di Anatomia Patologica, Università "La Sapienza", Roma, Italy

10.1136/annrheumdis-2001.329

Background Recent researches suggested a role of microchimerism in the pathogenesis of systemic sclerosis and Graft Versus Host Disease.

Objectives Aim of the present study was to evaluate whether fetal microchimerism plays a role in the pathogenesis of Sjögren's syndrome (SS).

Methods We looked for male microchimerism in minor salivary glands tissue from 6 women with SS and at least one male pregnancy or miscarriage. SS diagnosis was made according to EEC criteria. As control we used DNA from minor salivary biopsy of 3 women with SS and female pregnancies only, 1 woman with SS without previous pregnancies and 2 healthy women, one with a male pregnancy and one with a female pregnancy. We assayed by PCR for a specific Y chromosome sequence, SRY, and for the homologous gene of Amelogenin.

Results We didn't find male DNA neither in the tissue from women with SS and male pregnancy nor in the controls.

Conclusion This preliminary study doesn't support the hypothesis of a role of microchimerism in the pathogenesis of Sjögren's syndrome, however further analysis should be performed to better clarify the hypothetical association between microchimerism and SS.

\section{OP0070 NON-MALIGNANT LYMPHOPROLIFERATION IN SJOEGREN'S SYNDROME: PROPOSED CLASSIFICATION BASED ON INTEGRATED CLINICO-PHATOLOGIC AND MOLECULAR STUDIES AND FOLLOW-UP}

${ }^{1} S$ De Vita, ${ }^{2} \mathrm{C}$ Scott, ${ }^{1} \mathrm{M}$ Fabris, ${ }^{1} \mathrm{R}$ Damato, ${ }^{1} \mathrm{~A}$ Perin, ${ }^{1} \mathrm{~S}$ Sacco, ${ }^{1} \mathrm{GF}$ Ferraccioli. ${ }^{1}$ Division of Rheumatology-DPMSC, University of Udine, Udine, Italy; ${ }^{2}$ Division of Pathology, University of Udine, Udine, Italy

\subsection{6/annrheumdis-2001.330}

Background Non-neoplastic B-cell lymphoproliferation (NNBLP) is a common feature in Sjoegre's syndrome (SS) and predisposes to non-Hodgkin's lymphoma (NHL). It is characterised by extranodal or nodal organ involvement or by the presence of an Mcomponent in biologic fluids, in particular mixed monoclonal cryglobulinemia (MMC).

Objectives To better address the issue of SS-NNLP of MucosaAssociated Lymphoid Tissue (MALT), usually involving the major salivary glands, we investigated 13 consecutive patients with primary SS and persistent parotid swelling $(12 \mathrm{~F}, 1 \mathrm{M}$; mean age 59.5 years).

Methods Clinical and pathologic results were integrated with molecular analyses of B-cell clonal expansion in synchronous and metachronous biopsies (mean follow-up: 5.3 years).

Results At baseline 6/13 patients presented a parotid MESA with lymphoproliferative lesion (Group 1) and 7/13 a MESA with fully benign lymphoid infiltrate (Group 2), according to strict pathologic criteria. ${ }^{1}$ Tissue B-cell clonal expansion was monoclonal in 5/6 cases in Group 1 and oligo-polyclonal in 6/7 cases in Group 2. B-cell NHL evolution was observed in $2 / 6$ cases in Group 1 and in 0/7 in Group 2. Only the 2 cases evolved into NHL presented previous molecular evidence of ongoing expansion of the same clone or clonal dissemination in multiple biopsies. By contrast, the clinical and laboratory features were not relevant either for the diagnosis of NNLP vs NHL or to predict NHL evolution. MMC was detected in 2/13 cases, not evolved into NHL.

Conclusion Pathologic features are crucial to distinguish between non-neoplastic and neoplastic extranodal LP in SS. Molecular analyses of B-cell clonal expansion appear relevant to identify a subset of patients with higher risk of NHL progression. When considering the whole spectrum of NNLP in SS and a practical diagnostic approch ("real" disease entities, ${ }^{1-3}$ ), the following classification is proposed: a) Fully benign lymphoproliferation: fully benign lymphoid infiltrates in MALT sites or reactive lymphoadenopathy in the lack of M-component; b) Lymphoproliferative disorder: lymphoproliferative lesions in MALT sites, nodal atypical lymphoproliferative disorder or persistent MMC or Mcomponent in biologic fluids. A consensus on the classification of NNLP in SS will allow cooperative studies to clarify disease pathobiology and the risk of NHL evolution and to optimise follow-up and treatment.

\section{REFERENCES}

1 De Vita, et al. Arthritis Rheum. 1997;40:318

2 Skopouli, et al. Semin Arthritis Rheum. 2000;29:296

3 De Vita, et al. Arthritis Rheum. 2000;43:94

\section{Spondylarthropathies including psoriatic arthritis}

\section{AB0122 PREVALENCE OF SPONDYLARTHROPATHY AND PREDICTION OF ANKYLOSING SPONDYLITIS IN PATIENTS PRESENTING WITH INFLAMATORY BACK PAIN}

B Heidari. Department of Medicine, Shaheed Beheshti Hospital, Babol, Iran

10.1136/annrheumdis-2001.331

Background Back pain is a common symptom. It is one the first manifestations of ankylosing spondylitis (AS), which is also included in many sets of diagnostic criteria for spondylarthropathies (SPA). Definitive diagnosis of AS requires the presence of radiologic sacroiliitis, but its appearance lasts many years, so isolation of AS related back pain among patients with inflammatory back pain (IBP) is difficult and needs complete clinical examination with regard to specific signs and symptoms of AS.

Objectives The objective of this study is to assess the prevalence of SPA and AS in patients with IBP and to predict the diagnosis of AS on the basis of clinical findings.

Methods The study patients were seen in Shaheed Beheshti hospital clinic since 1994-1998. All patients presented with IBP which was confirmed clinically according to the criteria proposed by Clain et al. Patients assessment included, taking history, complete clinical examination for clinical sacroiliitis, buttock pain, arthritis, enthesitis, spinal mobility and chest expansion. Limitation of spine mobility and chest expansion was measured by standard tests. Pelvic radiograph was performed for all patients and appropriate diagnostic tests were requested as needed.

Diagnosis of SPA and AS was confirmed by European Spondylarthropathy study Group (ESSG) criteria and the modified New York criteria respectively. Patients with history of spinal trauma, surgery, infectious, degenerative and neoplastic diseases of the spine were excluded from the study. 
Results Variables analysed for association of IBP with AS, reduction of chest expansion and limitation of the lumbar spin During the study period. 103 patients (52 males, 51 females) entered the study. the mean age of onset of IBP was $29 \pm 7$ (range 1254) years, and the mean of the disease duration was $6 \pm 5$ (range, 0,5-20) years. Clinical examination revealed, arthritis in $20 \%$, clinical sacroiliitis $35 \%$, buttock pain $32 \%$, enthesitis $58 \%$, limitation of motion of the lumbar spine $54 \%$, limited chest expansion 53\%, radiographic sacroiliitis 60\%, and HLA- B27 positive in 18 of $27(67 \%)$.

$83 \%$ of patients met the ESSG criteria for SPA and 58\% met the modified New York criteria for definite AS. Limitation of motion of lumbar spine and reduced chest expansion observed in $54 \%$ and $53 \%$ of patients respectively. 14 of 18 patients with AS carried HLA - B27(78\%).

Among the many e motions were the best predictors of the diagnosis of AS, by odds ratio of 3 and 4 respectively.

Conclusion The results of the present study show that, the majority of IBP beginning at the third or forth decades of the life are due to SPA, and limitation of motions of spine and reduced chest wall expansion heralds the occurrence of AS.

\section{REFERENCES}

1 van der Linden S, van der HeijdeDM. Ankylosing spondylitis and other B27 related spondylarthropathies. Balliers Clin Rheumatol. 1995;9:355-71

2 Clain A, Fries JF. Clinical history as a screening test for ankylosing spondylitis. JAMA 1977;237:2613-14

3 Clain A. Spondylarthropathy, undifferentiated spondylarthritis and overlap. In: Madison PJ, et al., eds. Oxford textbook of rheumatology. Oxford University Press, 1998: $1037-48$

\section{AB0123 OBSTRUCTIVE SLEEP APNOEA (OSA) AND FATIGUE IN ANKYLOSING SPONDYLITIS (AS)}

${ }^{1} \mathrm{NX}$ Erb, ${ }^{1} \mathrm{D}$ Karokis, ${ }^{1} \mathrm{~K}$ Raza, ${ }^{2} \mathrm{M}$ Cushley, ${ }^{1} \mathrm{GD}$ Kitas. 'Department of Rheumatology; ${ }^{2}$ Department of Respiratory Medicine, Dudley Group of Hospitals NHS Trust, Dudley, UK

\subsection{6/annrheumdis-2001.332}

Background Fatigue is a common symptom and an indicator of disease activity in AS, but its pathogenic basis is poorly understood. ${ }^{1}$ It is also a cardinal symptom of OSA. ${ }^{2}$ AS may contribute to OSA through reduction of upper airway size $(10 \%$ involvement of temporomandibular joints-TMJ), cervical spine (CS) involvement leading to cord or medulla compression, or chest wall involvement leading to poor respiratory pattern.

Objectives Assessment of the prevalence of OSA in AS and its association with fatigue.

Methods 22 consenting, random AS out-patients were prospectively recruited. 3 did not attend for assessment. 19 patients [16 males, 3 females; age 43.7 years (31-69)] were assessed using: full clinical examination, Body Mass Index (BMI), Chest, CS and TMJ x-rays, Bath Ankylosing Spondylitis Activity Index (BASDAI), Hospital Anxiety and Depression Scale (HAD), Epworth Sleepiness Scale (ESS), Bed Partner Questionnaire, full Lung Function Tests, sleep studies (2 consecutive nights using EDEN Trace).

Results 11 patients had normal lung function, 6 had a typical and 2 a borderline restrictive pattern. ESS: mean 10 (2-20). 2 patients $(10 \%)$ fulfilled criteria for OSA: one had retrognathia, the other no obvious cause. Both received CPAP therapy with great improvement in fatigue and Epworth Sleepiness Scale and normalisation of oximetry. There were no associations with AS duration or activity, HAD, CS involvement, TMJ involvement or BMI.
Conclusion OSA affects $2 \%$ of the general population. ${ }^{3}$ Its prevalence in AS appears higher, but no definite conclusions can be drawn from this study. In isolated AS cases, OSA may be an important contributor to fatigue and, in the presence of relevant symptoms, it should be actively investigated and treated.

\section{REFERENCES}

1 Jones SD, Koh WH, Steiner A, Garrett SL, Calin A. Fatigue in ankylosing spondylitis: its prevalence and relationship to disease activity, sleep, and other factors. J Rheumatol. 1996;23:487-90

2 Skomro RP, Kryger MH. Clinical presentations of obstructive sleep apnea syndrome. Prog Cardiovasc Dis. 1999:41:331-40

3 Odens ML, Fox CH. Adult sleep apnea syndromes. Am Fam Physician 1995;52:859-66, 871-2

\section{AB0124 HELICOBACTER PYLORI - A POSSIBLE TRIGGER OF REACTIVE ARTHRITIS}

MD Parvu, C Tanasescu, A Barbulescu, G Gheorghe, C Ciubotaru. Internal Medicine, "Colentina" University Hospital, Bucharest, Romania

10.1136/annrheumdis-2001.333

Background The clinical evidence to support the role for bacteria in arthritogenesis has been confined to reactive arthritis (ReA) among of spondyloarthropathies. There are several bacteria associated with arthritogenesis such as Chlamydia trachomatis and enteropatogenic bacteria. However there are few reports regarding the pathogenic role of the infection with Helicobacter pylori (HP) in ReA.

Objectives The aim of the study is to investigate the possible pathogenic role of the infection with HP as a trigger of ReA.

Methods Ten patients (7 women, 3 men, aged among 19 to 57 years old) with ReA related to HP were investigated. These were identified by positive IgG and IgM antibodies agains HP using Elisa tests performed on sera obtained from one year study (01.01.1999-01.01.2000) on 18 patients with clinical picture suggestive of ReA. We also performed complex immunology investigations, $\mathrm{x}$-rays and osteoarticulary scintigraphies, endoscopy, but unfortunately no IgG antibodies against CagA or serum IgG levels against heat shock protein of 60KDA (HSP60). As for the rest of 8 patients with ReA, 2 of them were induced by $\mathrm{C}$ trachomatis, 3 by Yersinia enterocolitica serotip 03,09, 2 by Shigella flexneri and 1 by Salmonella enteritides, confirmed by specific IgM and IgG Elisa tests. All patients were HLA B27 negative.

Results The 10 HPReA patients had a female prevalence (7 women to 3 men) with young age (32 years old median), a high number of active joints 4 to 6 , long duration of arthritis (3 weeks), no fever and occasionally gastroduodenal complains. However not only peripheral joint involvement but also sacroiliac one was determined by osteoarticulary scintigraphy which was concordant with the high value of erythrocyte sedimentation rate (30 up to $86 \mathrm{~mm} / \mathrm{h}$ ) and C-reactive protein (7 cases). $50 \%$ of the cases were ANA positive, homogenous. As for the gastroduodenal involvement only 1 case had active duodenal ulcer HP positive, 2 gastric hyperemia with HP positive tests and 7 cases with normal aspects found at endoscopy.

Conclusion HP may be considered a possible trigger of ReA beyond Chlamydia trachomatis and enteropatogenic bacteria. The homology between microbial and human HSP60 may play a role in the pathogenesis of autoimmune mechanisms/disorders. There is no strong association between gastroduodenal involvement and ReA (different CagA status?). Further studies must be performed. 